\title{
CD-4/CD-8 lymphocytopenia in HIV negative patients with severe, chronic granulomatous infections
}

\author{
RC Kimbrough MD, RE Winn MD, S Issarachai MD, S Suwanvecho MD
}

\section{AbstRact}

Background: CD-4 lymphocytopenia can occur in acquired immunodeficiency syndrome (AIDS), in severe combined immunodeficiency, with the use of corticosteroids and/or immunosuppressive drugs, and in patients with idiopathic CD-4 lymphocytopenia. The mechanism for the lymphocytopenia is different in each of these illnesses.

Objective: Description of HIV-negative patients with severe disseminated tuberculosis or coccidioidomycosis and lymphocytopenia.

Settings and patients: All patients were referred to a University Medical Center in Northwest Texas, USA. Four had disseminated tuberculosis, and three had disseminated coccidioidomycosis.

Main outcome measures: Follow-up of lymphocyte subset counts and clinical improvement with the treatment of the underlying granulomatous infection.

Results: Five patients had an increase in both $C D-4$ and $C D-8$ lymphocyte subset counts with treatment of the underlying granulomatous infection. All patients had clinical improvement with initial therapy of the granulomatous infection. One patient succumbed to disseminated tuberculosis (meningitis) and two to disseminated coccidioidomycosis. One patient was lost to follow up.

Conclusions: We report a group of HIV-negative patients who had CD-4 lymphocytopenia in response to severe, disseminated, chronic granulomatous infections. With the treatment of the granulomatous infection the lymphocytopenia improved. This finding, coupled with preserved $C D-4 / C D-8$ ratios, can help to differentiate these patients from those with other causes of lymphocytopenia or AIDS.

Key words: granulomatous infection, tuberculosis, lymphocytopenia, CD4-lymphocytes, coccidioidomycosis

Corresponding author: Richard Winn MD

Contact Information: Richard.winn@ttuhsc.edu

DOI: $10.12746 /$ swrccc 2016.0415.196 


\section{INTRODUCTION}

CD-4 is a transmembrane glycoprotein found on T-helper lymphocytes, megakaryocytes, megakaryocyte precursors, erythroid precursors, and occasionally with small expression on other lymphocyte subsets. Human immunodeficiency virus (HIV) infects the T-helper lymphocyte by binding to the CD-4 molecule in association with co-receptors, such as chemokine receptors CCR5 or CXCR4. CD-4 lymphocytopenia is an indicator of advanced HIV infection but can also develop in inherited diseases, such as severe combined immunodeficiency, with the use of immunosuppressive drugs or corticosteroids, or in the rare condition of idiopathic CD-4 lymphocytopenia. ${ }^{1-4}$

We have identified a group of patients with unexplained CD-4 lymphocytopenia associated with severe disseminated tuberculosis or disseminated coccidioidomycosis. They all had low CD-4 and CD-8 counts with preserved CD-4/CD-8 ratios. The CD-4 counts improved with adequate treatment of the underlying granulomatous infections. Patients with low CD-4 counts and low CD-4/CD-8 ratios are susceptible to multiple opportunistic infections and malignancies. However, our patients had improvement of both CD-4 and CD-8 lymphocytopenia with the treatment of the granulomatous infection. These characteristics help differentiate these patients from other causes of CD-4 lymphocytopenia leading to opportunistic infections.

\section{Methods}

All patients were independently referred for evaluation and treatment of chronic granulomatous infections and CD-4 lymphocytopenia. All patients were seen at Texas Tech University Health Science Center and University Medical Center Hospital in Lubbock, TX.

HIV disease was excluded with a negative HIV-1 and HIV-2 enzyme immunoassay and Western blot assays. Some results were confirmed by multiple additional tests, including p24 antigen, HIV RNA by polymerase chain reaction (PCR), or HIV culture. None of the patients had a known immunodeficiency or had used immunosuppressive drugs or corticosteroids.
HIV-1 and HIV-2 enzyme immunoassays (HIV-1/HIV2 EIA kit, Abbot Laboratories, Abbott Park, IL) were performed according to established methods. Western Blot assays were sent to Quest Laboratory (California). HIV culture, p24 antigen, and HIV RNA PCR were sent to Nichols Institute (California). Lymphocyte immunophenotyping was performed by flow cytometry at our flow cytometry laboratory with the use of monoclonal antibody panels supplied by Coulter Corporation (Florida) with recommended techniques. The specimens were analyzed on the Coulter Epics $\mathrm{XL}$ flow cytometer.

We defined CD-4 lymphocytopenia as a CD-4 lymphocyte count fewer than 600 cells per mm3 (0.6 $\left.X 9^{9} / \mathrm{L}\right)$. We recognize that this number is above that used for the definition of AIDS. We defined an abnormal CD-4/CD-8 ratio as less than 1.2, the same definition as in HIV patients. Complete blood counts and blood chemistries were performed by standard methods

\section{Patient Results}

Six men and one woman were identified (Table). Four men had disseminated tuberculosis, and two had disseminated coccidioidomycosis. The woman had severe disseminated coccidioidomycosis. The four patients with tuberculosis ranged in age from 45 to 54. One was Caucasian, and three were Mexican-American. The three patients with coccidioidomycosis were African Americans, with ages ranging from 18 to 44. All patients had negative HIV screening, negative Western Blot tests, and negative HIV RNA PCR. Patient \#2 had an initial positive HIV screening test. However, repeat screening tests were negative as were all confirmatory tests. All patients had a reduced number of CD-4 lymphocytes and a reduced number of CD-8 lymphocytes which led to preserved CD-4/CD-8 lymphocyte ratios. Five patients had improvement in their lymphocytopenia with standard treatment of their underlying granulomatous disease. Two patients with coccidioidomycosis died; one patient with tuberculous meningitis also died. One patient was lost to follow up after starting treatment. 
Table: CD-4 counts, CD-8 counts and CD4/CD8 ratios before and after treatment

\begin{tabular}{|c|c|c|c|c|c|c|c|}
\hline \multirow[b]{2}{*}{ No } & \multirow[b]{2}{*}{ Infection } & \multicolumn{3}{|l|}{ At Diagnosis } & \multicolumn{3}{|c|}{ After Treatment } \\
\hline & & $\begin{array}{l}\text { CD4+ } \\
\text { count } \\
\text { cells } / \mathrm{mm}^{3} \text { * }\end{array}$ & $\begin{array}{l}\text { CD8+ } \\
\text { count } \\
\text { cells } / \mathrm{mm}^{3 *}\end{array}$ & $\begin{array}{l}\text { CD4/CD8 } \\
\text { ratio }\end{array}$ & $\begin{array}{l}\text { CD4+ } \\
\text { count } \\
\text { cells } / \mathrm{mm}^{3 *}\end{array}$ & $\begin{array}{l}\text { CD8+ } \\
\text { count } \\
\text { cells } / \mathrm{mm}^{3} \text { * }\end{array}$ & $\begin{array}{l}\text { CD4/CD8 } \\
\text { ratio }\end{array}$ \\
\hline 1 & Tuberculosis & 216 & 72 & 3.00 & 415 & 124 & 3.35 \\
\hline 2 & Tuberculosis & 82 & $\mathrm{~N} / \mathrm{A}$ & $\mathrm{N} / \mathrm{A}$ & 560 & 289 & 1.75 \\
\hline 3 & Tuberculosis & 245 & 78 & 3.15 & 558 & 250 & 2.23 \\
\hline 4 & Tuberculosis $^{\#}$ & 381 & 83 & 3.86 & $\mathrm{~N} / \mathrm{A}$ & $\mathrm{N} / \mathrm{A}$ & $\mathrm{N} / \mathrm{A}$ \\
\hline 5 & Coccidioidomycosis & 591 & 222 & 2.67 & 793 & 404 & 1.96 \\
\hline 6 & Coccidioidomycosis & 228 & 198 & 1.26 & 386 & 278 & 1.39 \\
\hline 7 & Coccidioidomycosis" & 100 & 66 & 1.50 & $\mathrm{~N} / \mathrm{A}$ & $\mathrm{N} / \mathrm{A}$ & $\mathrm{N} / \mathrm{A}$ \\
\hline
\end{tabular}

N/A - not available; ${ }^{*}-0.001$ X I $109 / \mathrm{L} ;{ }^{\#}$ - died

\section{Discussion}

Patients with HIV disease have low CD-4 lymphocyte subset counts and reversed CD-4/CD-8 ratios that worsen as the viral infection progresses and the clinical condition progresses toward AIDS. With treatment of the HIV infection the lymphocytopenia may improve. These patients are subject to opportunistic infections and opportunistic malignancies. Idiopathic CD-4 Iymphocytopenia is a rare condition with no cause for the immunodeficiency. Almost all of the patients reported had persistently reversed CD-4/ CD-8 ratios. These patients are also susceptible to opportunistic disease and after the treatment of the opportunistic illness (if present) they continue to have lymphocytopenia and a reversed CD-4/CD-8 ratios. ${ }^{1-4}$

We did not control for diurnal variations of lymphocyte counts and subsets. ${ }^{5}$ However, all of the lymphocyte counts were performed in the same laboratory using the same equipment and procedures. All of our patients with severe chronic granulomatous infections had CD-4 and CD-8 lymphocytopenia but normal CD-4/CD-8 ratios. Their lymphocytopenia improved with treatment of the underlying illness. Thus, our patients differ from those with advanced HIV infection, patients having lymphocytopenia due to other illnesses or drugs, and those with idiopathic CD-4 lymphocytopenia.

Similar findings have been reported in patients with tuberculosis, histoplasmosis, and other fungal infections. Other authors have reported CD-4 lymphocytopenia in a wide variety of infectious and noninfectious illnesses. ${ }^{5-10}$ There is one case report of profound T-lymphocytopenia in a dual infection with tuberculosis and Cryptococcus. ${ }^{11}$ Patients with severe tuberculosis and lymphocytopenia have recently been reported to have improvement in the lymphocyte counts with adequate treatment. ${ }^{12-13}$ However, the finding of disseminated tuberculosis coupled with lymphocytopenia indicates a poor prognosis. ${ }^{14}$

There are multiple hypotheses for the cause of the lymphocytopenia in tuberculosis. 15-20 These range from "sequestration" to lymphocytopenia due to a catabolic state. Tuberculous infected macrophages secrete several inflammatory cytokines and may stimulate accessory cells, such as endothelial cells, to secrete additional inflammatory cytokines. ${ }^{15} \mathrm{~A}$ combination of these cytokines can stimulate or suppress lymphocyte blastogenesis. Recent in vitro studies have shown that $\mathrm{M}$. tuberculosis affects monocyte-derived dendritic cells. This may down 
regulate the $T$ helper response to infection. ${ }^{18-22} \mathrm{Im}$ munosuppression in tuberculosis may also be associated with increases and decreases of multiple growth factors. ${ }^{23}$ Other viral infections may cause lymphocytopenia. ${ }^{24-25}$

\section{Conclusion}

In conclusion, we report a group of HIV-negative patients who have CD-4 and CD-8 lymphocytopenia in response to severe, disseminated, chronic granulomatous infections. With treatment of the granulomatous infections the lymphocytopenia improved. This finding coupled with preserved CD-4/CD-8 ratios can help differentiate these patients from those with other causes of lymphocytopenia and AIDS.

\begin{abstract}
Author Affiliations: S Issarachai and S Suwanvecho were residents in Internal Medicine at Texas Tech University Health Sciences Center in Lubbock, TX. RC Kimbrough (deceased) and RE Winn are faculty members in Infectious Disease in the Department of Internal Medicine.
\end{abstract}

Submitted: $2 / 22 / 2016$

Accepted: 5/26/2016

Reviewers: David Griffith MD

Published electronically: 4/15/2016

Conflict of Interest Disclosures: None

\section{REFERENCES}

1. Smith DK, Neal JJ, Holmberg SD. Unexplained opportunistic infections and CD4+ T-lymphocytopenia without HIV infection. New England J Med 1993; 328: 373-379.

2. Ho DD, Cao Y, Zhu T, et al. Idiopathic CD4+ T-lymphocytopenia- immunodeficiency without evidence of HIV infection. New England J Med 1993; 328: 380-385

3. Spira TJ, Jones BM, Nicholson JKA, et al. Idiopathic CD4+ T-lymphocytopenia - an analysis of five patients with un- explained opportunistic infections. New England J Med 1993; 328: 386-392

4. Duncan RA, von Reyn F, Alliegro GM, Toossi Z, Sugar AM, Levitz SM. Idiopathic CD4+ T-lymphocytopenia - four patients with opportunistic infections and no evidence of HIV infection. New England J Med1993; 328: 393-398.

5. Laurence J. T-cell subsets in health, infectious diseases and idiopathic CD4+ T-lymphocytopenia. Annals of Intern Med 1993; 119: 55-62.

6. Beck JS, Potts RC, Kardjito T, Grange JM. T4 lymphopenia in patients with active pulmonary tuberculosis. Clinical Experience Immunology 1985; 60: 49-54.

7. Jones BE, Oo MM, Taiwel EK, et al. CD4 cell count in human immunodeficiency virus - negative patients with tuberculosis. Clinical Infectious Diseases 1997; 24: 988-991.

8. Lehmann PF, Gibbons J, Senitzer D, Ribner BS, Freimer EH. T-lymphocyte abnormalities in disseminated histoplasmosis. American J Internal Medicine 1983; 75: 790-794.

9. Seligmann M, Autran B, Rabian C, et al. Profound and possibly primary "idiopathic CD4+ lymphocytopenia" in a patient with fungal infections. Clinical Immunology Immunopathology 1994; 71: 203-207.

10. Williams RC, Koster FT, Kilpatrick KA. Alterations in lymphocyte cell surface markers during various human infections. American J Medicine 1983: 75: 807-816.

11. Zaharatos GJ, Behr MA, Libman MD. Profound T-lymphocytopenia and cryptococcemia in a human immunodeficiency virus negative disseminated tuberculosis. Clinical Infectious Disease 2001; 33: e 125-128.

12. Pilheu JA, De Salvo MC, Gonzalez J, Rey D, Ellas MC, Ruppi MC. CD4+ T-lymphocytopenia in severe tuberculosis without evidence of human immunodeficiency virus infection. International J Tuberculosis and Lung Disease 1997; 1:422-426 13. Uppal SS, Tewari SC, Verma S, Dhot PS. Comparison of CD-4 and CD-8 lymphocyte counts in HIV-negative pulmonary TB patients with those in normal blood donors and the effect of antitubercular treatment: hospital-based flow cytometric study. Cytometry Part B: Clinical Cytometry 2004; 61: 20-26

14. Aziz S, Al-Anazi AB, Al-Hediathy MA, Al-Shobaili HA, Al-Aska AL Mycobacterium tuberculosis and CD-4+ T-lymphocytopenia. a grave combination. Saudi Medical J 2005; 26: $1655-1657$

15. Ellner JJ. Review: The immune response in human tuberculosis - implications for tuberculosis control. J Infectious Disease 1997; 176: 1351-1359.

16. Onwubalili JK. Untreated tuberculosis may be associated with lymphocytopenia, not lymphocytosis. Afr J Medicine Medical Science 1990; 19: 181-183.

17. Maartens G, Willcox PA, Benatar S. Miliary tuberculosis: rapid diagnosis, hematologic abnormalities, and outcome in 
109 treated adults. American J Medicine 1990; 89: 291-296.

18. Glasser RM, Walker RI, Herion JC, Hill C. The significance of hematologic abnormalities in patients with tuberculosis. Arch Internal Medicine 1970; 125: 691-695.

19. Bagby GC, Gilbert DN. Suppression of granulopoiesis by t-lymphocytes in two patients with disseminated mycobacterial infection. Annals of Internal Medicine 1981; 94 (part 1): 478-481.

20. Morris CD, Bird AR, Nell H. The haematological and biochemical changes in severe pulmonary tuberculosis. Quarterly Journal of Med 1989; (New Series) 73: 1151-1159.

21. Hanekom WA, Mendillo M. Manca C, Haslett PAJ, Siddiqui MR, Barry C, Kaplan G. Mycobacterium tuberculosis inhibits maturation of human monocyte-derived dendritic cells in vitro. J Infectious Diseases 2003; 188:257-266

22. Natarajan K, Latchumanan VK. Singh B, Singh S, Sharma P. Down-regulation of T helper 1 responses to mycobacterial antigens due to maturation of dendritic cells by $10 \mathrm{kDa}$ Mycobacterium tuberculosis secretory antigen. J Infectious Diseases 2003; 187: 914-928.

23. Roberts T, Beyers N, Aguirre A, Walzl G. Immunosuppression during active tuberculosis is characterized by decreased interferon-gamma production and CD25 expression with elevated Forkhead Box P3 transforming growth factor-beta, and interleukin-4 mRNA Levels. J Infectious Diseases 2007; 195:879878.

24. Park K, Monk BJ, Wilczynski S. Ito JI, Vasilev SA. Idiopathic CD4+ T-lymphocytopenia and recurrent vulvar intraepithelial neoplasia. Obstetrics and Gynecology 1994; 84; (part 2): 712-714.

25. Setson CL, Rapini RP, Tyring SK, Kimbrough RC. Disseminated human papilloma virus infection with idiopathic CD4+ T-lymphocytopenia. J Cutaneous Pathology 2000; 27: 574. 